\title{
Work and Teamwork Transparency an Ergonomic Assessment in Operating Room Facilities
}

\section{Conference Paper}

\section{Author(s):}

Held, Jürgen (D); Krueger, Helmut

Publication date:

2000-07

\section{Permanent link:}

https://doi.org/10.3929/ethz-b-000300429

\section{Rights / license:}

In Copyright - Non-Commercial Use Permitted

\section{Originally published in:}

Proceedings of the Human Factors and Ergonomics Society Annual Meeting 44(33), https://doi.org/10.1177/154193120004403344 


\title{
WORK AND TEAMWORK TRANSPARENCY ${ }^{1}$ AN ERGONOMIC ASSESSMENT IN OPERATING ROOM FACILITIES
}

\author{
Jürgen Held and Helmut Krueger \\ Institute of Hygiene and Applied Physiology \\ Swiss Federal Institute of Technology Zurich, Switzerland
}

The objective is to analyse anaesthesia workplaces in a multidisciplinary operating room facility, to understand the causes for problematic work procedures and to decide for improvements. The analysis include: observations, computerised recording of tasks and movements with the FIT-System, video and photo documentation. Documents are designed to confront the users with their own work situation and to support the explication of their knowledge in a semi-structured interview.

The results are important lacks in: the misplaced devices outside of the human's zones of reach and view, the difficult procedures to attach the lines between the patient and the devices and inconsistent workplace layouts. The causes therefore are design decision faults during the installation of the facility. The decisions for improvements are: the development of a new concept for a flexible equipment positioning and the design of a tool for cable handling.

The discussion is, that from the project's beginning the users mentioned the handling of the cables and lines as the mainly cause for work difficulties. But the outstanding ergonomist had a broader view of problems. The used method invokes a mutual (ergonomist and users) learn process and results in a common understanding of the problem's background.

\section{INTRODUCTION}

\section{Where is the Patient? Where is Ergonomics?}

Operating Rooms (OR) are environments of high technology, where human operator or equipment failures have disastrous consequences for the patient's health. Here, as well as in intensive care facilities, an ergonomic design of the devices and the workplaces is related not only to the worker's health but although to the patient's safety. It guarantees the best and most economic use of the skills of physicians and nurses. Furthermore it results in a positive impact to the over all work quality and efficiency of the work procedure.

But the patient is often hidden by an high amount of randomly placed devices. The physician-machine interface mismatches most of the user's requirements and shows overall a lack of ergonomic and systematic concepts. The question is: Why? What are the reasons for mismatching ergonomic principles?
A project of workplace improvement was carried out to clarify this. Object of analysis are anaesthesia's workplaces in a multidiscipline surgery facility.

\section{METHOD}

1. Status quo analysis Inspection of the workplaces, observation of work procedures, photo/video documentation.

2. Work analysis with the FIT-System

The FIT-System (Flexible Interface Technique) is for multi-purpose recording of observational data (Held \& Krueger, 2000a). Objectives are:

- The anaesthetist's tasks during surgery.

- The team members movements during the process of patient preparation/induction.

- The distribution and allocation of tasks in the team work of preparation/induction.

- The observations (head movements) during the intra-operative work stage.

\footnotetext{
${ }^{1}$ In: Proceedings of the IEA 2000/HFES 2000 Congress, Vol. 6, pp. 241 - 244.
} 


\section{Expert-Users Interviews}

A semi-structured or narrative interview with at all 22 questions. Three of them for a rating about the layout and the usability of the OR equipment. The rest for the description of work procedures, tasks classification, work problems and ideas of improvement. All questions are combined with material to show the context, i.e. photographs and layout plans. Interview duration is one hour.

\section{RESULTS}

\section{Status Quo Analysis}

The most important technical devices for the anaesthetist are the respirator and the monitor of the patient's vital signs. The status quo at all work places (8 operating rooms) shows, that the monitor is placed on a ceiling device. It's position is behind a beam of media support under the ceiling. The respirator stands on a moveable trolley on the floor (figure 1).

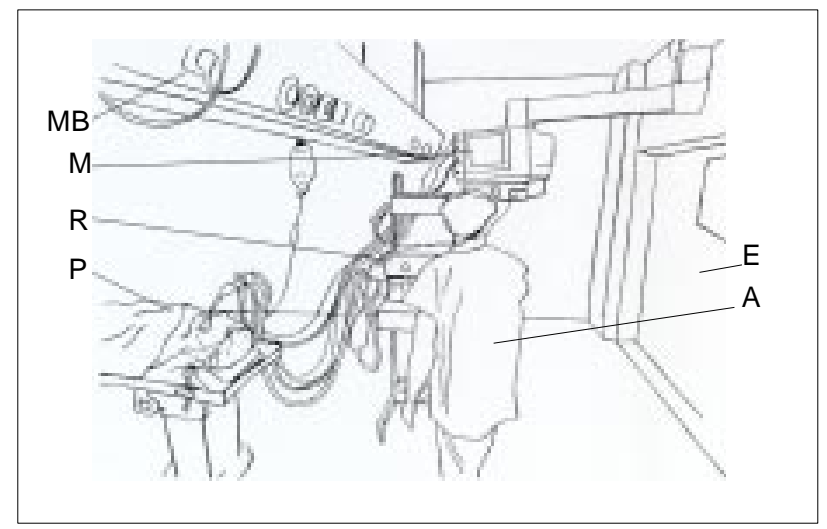

Figure 1: Status quo of work place layout in the OR. Entrance door (E), Anasthetist (A), Patient (P), Respirator (R), Monitor (M) and the media beam (MB) under the ceiling.

\section{FIT-System Analysis}

a) Time to tasks - intraoperative

In the four observations (routine cases), the anaesthetist spend during the surgical procedure $22 \%$ time (deviation 3\%) for to control and manipulate the monitor and respirator and $26 \%$ time for the tasks related to the patient (figure 2).

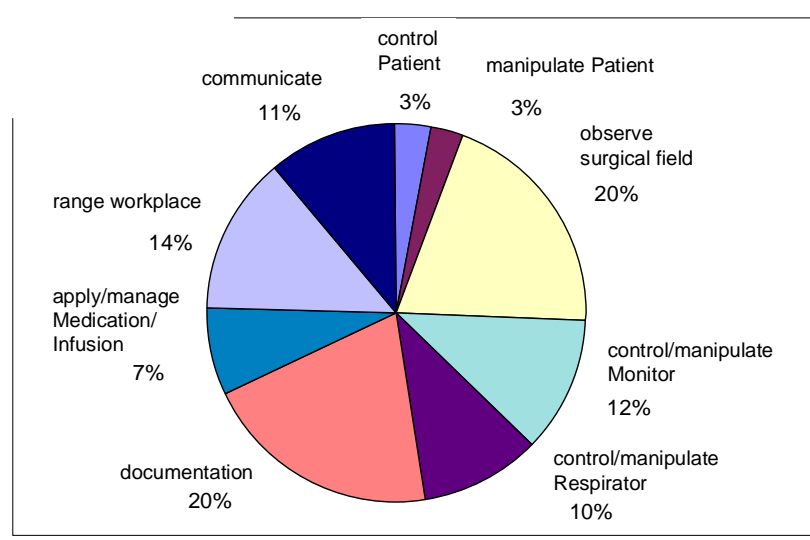

Figure 2: Mean values of the time sums (four surgical procedures) needed for the anaesthetist's tasks.

b) Movements of team members

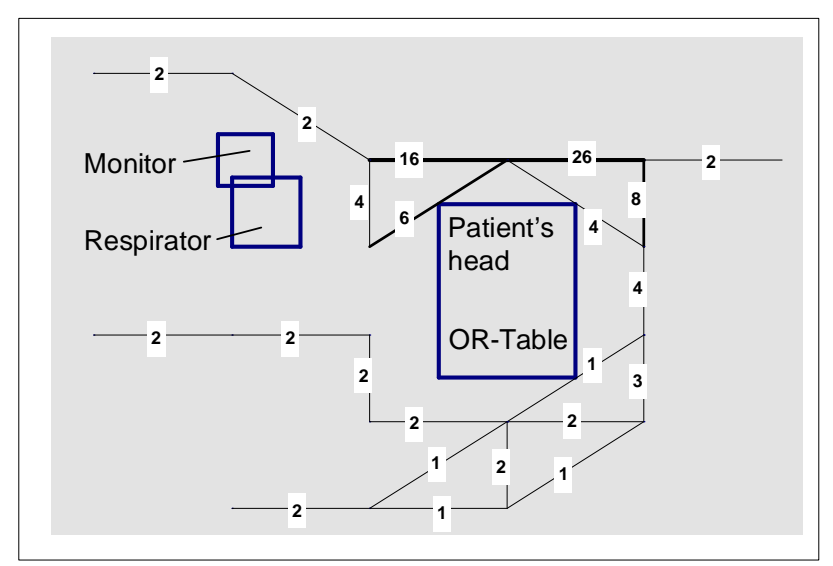

Figure 3: The walk of an anaesthetist during preparation and induction of the patient. Lines represent the paths, the numbers the frequencies of passages.

Ten anaesthesia teams were analysed. Each team includes an anaesthetist and one to two anaesthesia nurses. The results FIT-System analysis shows no correlation but a high diversification in the movements or links of the team members.

\section{c) Observations - Head Movements}

In a FIT-System inspection during surgery, the anaesthetists changes in 200 minutes 118 times his observation focus between patient and monitor. In a further inspection he changes his observation focus in 170 minutes 1200 times from one place to another. 208 head movementsbetween the monitor and the handheld protocol were registered in 57 intervals. d) Distribution of tasks in the team work 
The inspection of task to team member distribution shows an high amount of small activities. Dominant is the task „range the work place“ (figure 4).

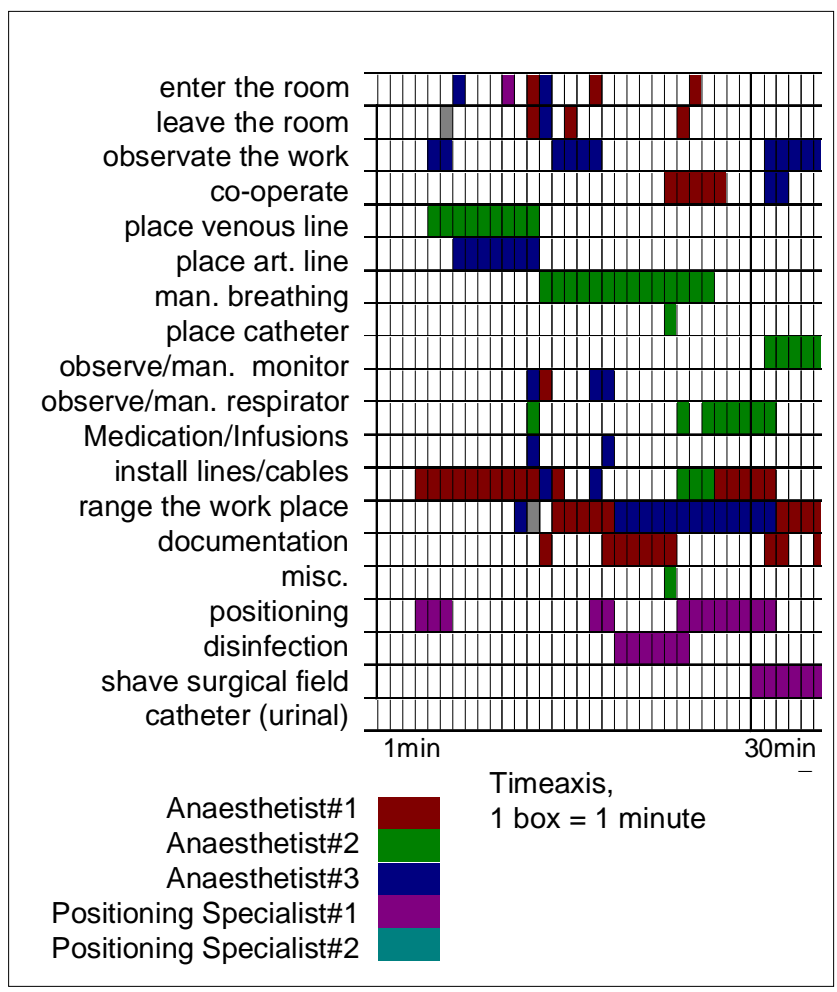

Figure 4: FIT-System teamwork analysis (extract) of the work process to prepare the patient and induct anaesthesia.

\section{Expert-User Interviews}

Interview partners were 18 physicians and nurses of the anaesthesia profession. On a five-item scale between: $1=$ good and 5=less good, 12 of 18 rated the equipment arrangement as good (mean rating: 1.6). In relation to this evaluation, the most important problem was mentioned in the difficult and time consuming cable and line attachment in the OR. But the positioning of the electronically devices was not mentioned as a reason for attachment difficulties. In contrary to this, the users gave in the more narrative and semi-structured part of the interview an high amount of comments and ideas of improvements for the device positioning.

\section{Visualisation of the analysis's results}

The results are presented to the anaesthetists and nurse anaesthetists at staff meetings (figure 5).

Consensus was the decision to develop a new concept for monitor positioning and to design a tool to facilitate the cable handling.

\section{DISCUSSION}

\section{The Speedometer at the Back Seat}

The anaesthetist has to observe a lateral workspace in the operating room of 140 degree.

There is no chance to place the monitor near to the patient because of the media beam who blocks the monitor at his position in the backstage. The monitor's screen is placed more than $6.5 \mathrm{ft}$. above the ground. In a lower position the monitor is an hindrance and causes head aches for the anaesthesia team members.

Monitor and other devices requires an high amount of time (figure 2). This and the frequency of observations make clear, that the work situation means driving a car while the speedometer is placed at the back seat.

\section{The Problem of Problem Recognition}

The interview results demonstrate that the expert's problem recognition (the monitor is the problem) had nothing together with the user's process of understanding (the spaghettis of cables are the problem). In this context any directive like: „Please change the monitor position!" must lead to a lack of acceptance of the proposed changes. At this point of the project it is as difficult to wait, as it is clear (for the ergonomist) that most problems mentioned by the users are connected to the layout of the work places.

But the project shows the advantage of patience in a mutual learning process in the interview sessions. The use of semi-structured questions and material, i.e. photographs, sketches and data from the FITSystem analysis supported the situation awareness and verbalisation of the user's knowledge. This effect can be described as „Thing-Think Interviews“ (see figure 6).

\section{Time and Materials to Learn}

Compared to the approach of a traditional consultant (,,You have to change the monitor 
position!“) more time and efforts were necessary to moderate the learning processes in theinterviews especially to prepare materials for confrontation and visualisation. The latter needs to have a ,self-

focusing appeal“ (ECO, 1987). For example: The users were not much interested in how many time they spend for the several tasks, as shown in figure 2. But the effect of confrontation was reached with images of their passages, as shown in figure 3 .

The same effect was reached with photo documents, snap-shots of work situations, especially bad work positions or situations of intersections.

It seems, that user-oriented disciplines like ergonomics need a good qualification in user-oriented visualisation. This is in fact design work, but: Before any activity of problem solving starts.

\section{To be aware of hidden Interpretations}

The worst case of expert-user communication is the unidirectional information (figure 5, situation A). The expertise is a result from the expert's way to recognise and interpret. Everyone will deny to use such approaches in ergonomics or design - it is a matter of course to have an information interchange (figure 5, situation B). But the risk is, that the mutual interpretations rests unspoken or hidden.

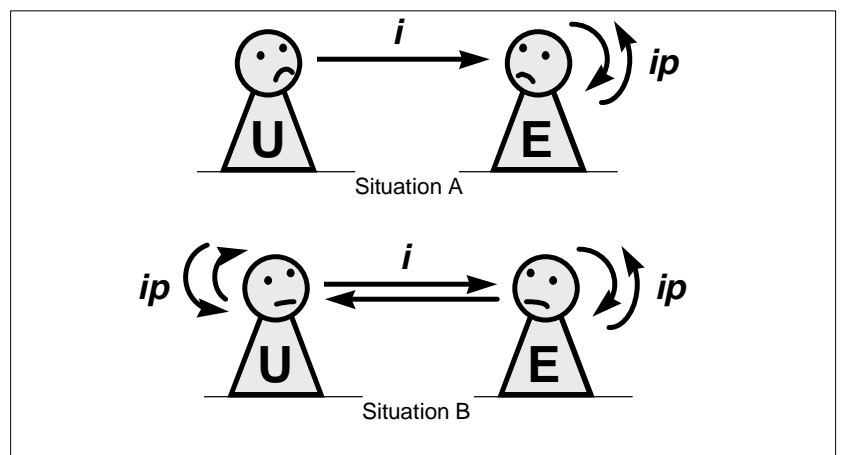

Figure 5: User-Expert information (i) processes and the risk of hidden interpretations (ip).

A certain strategy and principles (Held \& Krueger, $2000 \mathrm{~b}$ ) can initiate and moderate the co-operation of interpretations (figure 6).

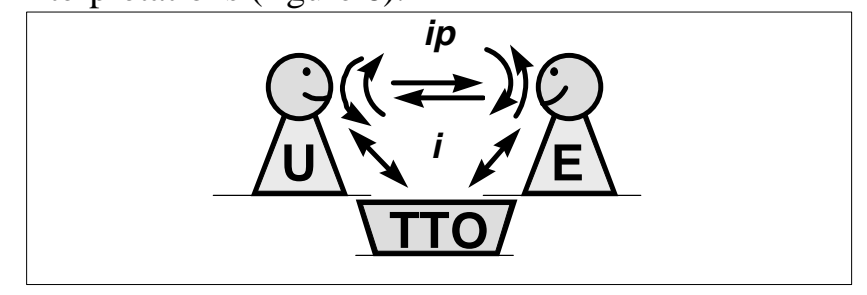

Figure 6: User -Expert interaction. Information (i) and co-operation of interpretations (ip) effected by „Thing-Think objects“ (TTO).

\section{CONCLUSION}

Participatory Ergonomics is a process where users and ergonomist together can solve over a long period of time work related problems (Held, 1998).

That requires qualification or learn processes in the beginning of a project and is often ignored in user-oriented approaches (ISO 13407, 1998). But then more time is needed to try to match the user's requirements in several cycles of trial and error and often such developments ended with the latter one.

Therefore it make sense to invest in a co-operation of interpretations before starting the co-operation of actions. Than design as problem solving isn't the problem but the right way to find an adequate problem recognition and understanding - that seems to be the challenge.

The users in the presented project conclude: „Thank you very much - we have learned a lot!“.

\section{REFERENCES}

Eco, U. (1987). Streit der Interpretationen.

Held, J. (1998). Partizipative Ergonomie - Die Prozessgestaltung zur Beteiligung Betroffener an ergonomischen Gestaltungsaufgaben. DISS ETH Nr. 12825, Zürich.

Held, J. \& Krueger, H. (2000a). The Ergonomic Observer - A new flexible Interface Technique for online Work and Teamwork analysis. In Proc. XIVth Triennial Congress of the International Ergonomics Association. San Diego 2000.

Held, J. \& Krueger, H. (2000b). In the Beginning...Principles and the B-fore Model for Participatory Ergonomics and Design. InProc. XIVth Triennial Congress of the International Ergonomics Association. San Diego 2000.

ISO 13407 (1998) Human-centred design processes for interactive systems. International Standard. 